\title{
Patterns and Determinants of Breast Feeding Practices in Dodoma Municipality: A Cross Sectional Study
}

\author{
Madan Mohan Laddunuri (Corresponding author) \\ Department of sociology and anthropology, Dodoma University, Tanzania \\ E-mail: madan.phd@gmail.com
}

Received: March 28, 2012 Accepted: July 3, 2012 Published: December 1, 2012

doi:10.5296/jfs.v1i1.1566 URL: http://dx.doi.org/10.5296/jfs.v1i1.1566

\begin{abstract}
Background :Promotion of proper breastfeeding practices for the first six months of life is the most cost-effective intervention for reducing childhood morbidity and mortality. The objective of the present study was to determine prevalence of EBF and understand the awareness of breast feeding practices among the women in Dodoma Municipality, central part of Tanzania.

Methods: A cross-sectional study was conducted in Dodoma municipality, Tanzania in April to May 2011. Multiple sampling methods were applied in selection of a sample 200(women aged 15-42 years). A structured interview schedule was used to collect information of Mothers with infants aged 0 to 12 months on demographic characteristics, knowledge of EBF, and details regarding breast feeding practices since birth of their children to six months of life.

Results: The prevalence of EBF among women in Dodoma Municipality, Tanzania was 59\%. Knowledge of EBF was relatively higher (89\%) compared to the prevalence of EBF (59\%). In total, majority $(89 \%)$ of the women in study area had initiated breastfeeding in first one hour of delivery. Hospital deliveries (67.5\%) higher than home deliveries in Dodoma municipality.

Conclusion: Though exclusive breastfeeding prevalence rate found higher than at national level which was encouraging but not satisfactory according to world health organizations recommendations. Interventions and further research should address the low prevalence of exclusive breast feeding practices in study area.
\end{abstract}

Keywords: Exclusive breastfeeding; Infant mortality; prevalence; Dodoma 


\section{Background}

The single most cost effective intervention to reduce infant morbidity and mortality in developing countries would be the promotion of exclusive breastfeeding. The estimated reduction of infant mortality by promoting exclusive breastfeeding is $13 \%$ [1]. Non-exclusive breastfeeding can increase the risk of death due to diarrhea and pneumonia among 0-6 month old infants by more than two times [2]. Benefits of exclusive breastfeeding up to six months duration have been studied all over the world and there are enormous amount of evidence to support this [2]. The World Health Organization recommended exclusive breastfeeding for six months in 2002 [3] and most of the international community has followed these guidelines [4]. However, in most countries a relatively small percentage of mothers practice optimal breast-feeding behaviors that reduce infants' risk of morbidity and mortality, including initiation of breast-feeding in the first hour after birth and exclusive breast-feeding for the first 6 months of life. Exclusive breastfeeding has been defined as feeding an infant with breast milk only without giving any other foods, not even water. There is a relaxation in definition and it allows prescribed medicines, immunizations, vitamins and minerals supplements [5].

Various factors associated with sub-optimal breastfeeding practices have been identified in various settings. These include maternal characteristics such as age, marital status, occupation, and education level, maternity health care; health education and media exposure, mode of delivery. [6].

Nevertheless, it is always considered that breastfeeding is related to social, cultural and traditional patterns of a given population. This fact justifies need for regional studies that allows more efficient action in regard to measures for intervention, based on knowledge of local reality. The present study was undertaken to: (i) study prevailing exclusive breast feeding practices, within the first six months of life the infants (ii) Understand the awareness of breast feeding practices among the women with up to six months children and (iii) define the socio-demographic factors affecting exclusive breast feeding practices in the first six months.

\section{Methods and Materials}

\section{Study area}

A community-based descriptive cross sectional study was conducted between April and May 2011 among women with infants aged 0 - 12 months in Dodoma Municipality. Dodoma municipality is the administrative capital of Tanzania and located in central part of the country. The municipality of Dodoma is subdivided in to 4 Divisions which are further divided in to 30 wards and 42 villages [7] (Table1). 
Table 1. Geographical description of Dodoma

\begin{tabular}{|l|l|l|}
\hline Division & Number of wards & Number of villages \\
\hline Urban (Mjini) Division & 17 & 7 \\
\hline Hombolo Division & 5 & 16 \\
\hline Kikombo Division & 3 & 7 \\
\hline Zuzu Division & 5 & 12 \\
\hline Total & 30 & 42 \\
\hline
\end{tabular}

The 17 wards of the Urban Division, has a total land area of $426 \mathrm{~km} 2$, has and a total population of 183,650 inhabitants. Dodoma Municipality is situated in an economically depressed area.

Although it has rich agricultural land, it is affected by harsh semi-arid climatic conditions, and rather traditional agricultural methods are still predominating. In the urban areas the main activities of the residents are commerce, urban farming and civil service employment while in the rural areas, crop farming and livestock keeping are the commonest means of livelihood.

Based on the 2002 National Population and Housing Census, the population of Dodoma was 324,347 people of whom 157,469 or 48.5 percent are males and 166,878, or 51.5 per cent are females. The estimated total number of households is 74,914 with an average household size of 4 people [8].

\section{Sampling procedure}

Administratively, the Dodoma Municipality, like other districts in Tanzania is divided into divisions, wards and finally into the hamlets (mitaa) in urban areas or villages in the rural areas. The hamlets are the smallest units consisting of about 20 to 40 households with a leader. The municipality has 4 divisions, 30 wards and a total of 42 villages.

A multi-stage sampling technique was used to select the respondents. The first stage involved a random selection of 10 wards out of 30 in Dodoma Municipality. Then 15 hamlets were randomly selected from each of the 10 selected wards. All the households from selected hamlets with women who met the inclusion criteria were listed out. From the list, 200 women with infants aged 0-12 months were selected randomly and invited to participate in the study and all agreed to participate.

\section{Interviews}

An interview is regarded as an interchange of views between two or more people on a topic of mutual interest and emphasizes the social situations of the research data. It is a research instrument for data collection that involves a collection of data through verbal interaction between the interviewee and the interviewer [9]. Structured interview schedule was used in obtaining data regarding socio-demographic characteristics of the participants, knowledge of EBF and prevalence of EBF by using a "recall since birth" method from the field. 


\section{Data processing and analysis}

Data were entered and analyzed using Statistical Package for the Social Sciences (SPSS) software for windows version 12.0. Knowledge of EBF was assessed using two questions; meaning or definition of EBF and recommended duration of six months. Respondents who answered both questions correctly were categorized as having 'adequate knowledge' of EBF. Prevalence of exclusive breastfeeding was measured using questions on breastfeeding duration of six months and feeding only breast milk to children.

\section{Results}

As shown in Table1, a total of 200 mothers were interviewed. The overall mean age was $24.56 \pm 5.32$ years. The age of the respondents ranged between 15 and 42 years. Majority of the mothers $(54.5 \%)$ were aged between 20 to 25 years. Most $(64.5 \%)$ of the mothers had primary school education $14 \%$ secondary school education while $21.5 \%$ were illiterate. Majority $(130,65 \%)$ of the mothers were house wives and rest of them were mainly traders (38, $19.0 \%)$ and civil servants $(31,15.5 \%)$.A total of $(157,78.5 \%)$ mothers were living or cohabiting with their husbands while $(28.7 \%)$ were living alone. It is seen from the table that the majority $(76 \%)$ of mothers had more than one child while few $(24 \%)$ of them had only one child and female /male babies' ratio was 1.08:1.00.More than two thirds $(67.5 \%)$ of the mothers had hospital deliveries while one third (32.5\%) delivered at home. Seventeen $(8.5 \%)$ deliveries were by caesarean section, and the rest $(183,91.5 \%)$ were normal vaginal deliveries.

Table 2 depicts knowledge of exclusive breastfeeding among the respondents. Most (193, 96.5\%) of the respondents having knowledge on "Meaning of 'Exclusive Breastfeeding" and they agreed that giving only breast milk to the children as exclusive breast feeding. Majority $(183,91.5 \%)$ of them having right knowledge on duration of exclusive breastfeeding as 24 weeks. On overall, Eighty nine percent of the respondents had adequate knowledge on the definition/meaning of EBF. There was no association between several socio-demographic factors (age, education, income, marital status or employment) with EBF knowledge. Highest number $(148,74.0 \%)$ of mothers getting breastfeeding education by government hospital but few $(32,16.0 \%)$ of them getting by private hospital, and remaining by Friends/relatives $(4.5 \%)$ and Media (5.0\%).

Table 3 illustrates the details of breastfeeding practices of mothers that most of women (178, $89 \%$ ) reported to have breastfed their infants within one hour after delivery but very few $(8 \%$ and $2 \%$ ) of them fed their milk to children within a day and next day of birth. More than half $(118,59 \%)$ of the respondents reported that they exclusively breastfed their infants for the period of six months.

Table 4 shows the association between EBF and socio-demographic characteristics of the respondents. Women had higher odds of exclusive breastfeeding if they were; employed ( $\mathrm{p}=$ $0.005)$, had adequate knowledge of EBF $(\mathrm{p}<0.001)$ and had delivered at a health facility $(\mathrm{p}<$ $0.001)$. 


\section{Discussion}

\section{Summary and key findings}

Breast feeding initiation should ideally be started within half an hour after delivery. Early initiation of breast feeding is important for mother-infant bonding, helps in establishment of longer and more successful breastfeeding. Most (89\%) of the infants in our study initiated breastfeeding within 1 hour. The prevalence of exclusively breastfeeding for six months was $59 \%$ in Dodoma Municipality. The study also showed that approximately $11 \%$ of the women had inadequate knowledge of EBF. It is found that prevalence of EBF higher than the national average of $41 \%$ [10], but still it is less than WHO recommendation which is $90 \%$ [11]. It is a well-known fact that exclusive breast feeding protects the child from malnutrition and infection. A Dhaka study showed that when EBF rates at 6 months were increased from 39\% to $70 \%$ there was a reduction in infant mortality by $32 \%$ which is quite significant [2]. Therefore there is a need to intensify community and hospital-based interventions which promote EBF in Dodoma Municipality.

Most (89\%) of the women having adequate knowledge of EBF in the study area and there is an influence of knowledge of EBF on prevalence of EBF. Due to the higher level of knowledge of EBF among women, higher the prevalence of EBF (59\%). 11\% of the women had inadequate knowledge of EBF. Mothers, who had knowledge of EBF, were about five times more likely to intend to breastfeed exclusively [5]. More efforts are needed to make women aware exclusive breast feeding practices.

Majority (135,67.5\%) of the women delivered at hospital and highest (91, 67.4\%) number of them breast feeding exclusively to their children. But prevalence of exclusive breast feeding is less among home delivered women (27,41.5\%).hospital delivery were strong determinants for EBF, even more than socio-demographic factors[12].Hospital-based breastfeeding promotion efforts might be cost effective to implement in Tanzania. At health facilities in Tanzania, breastfeeding guidelines require that health workers should help women to initiate breastfeeding immediately after delivery. They should also support women practically, with issues of attachment and how to hold the baby during breastfeeding [13].

\section{Conclusion}

The first and foremost inference of this study is that most (89\%) of the women was having knowledge about EBF but knowledge is not resembling with prevalence (59\%) of EBF for up to six months in study area. Although the exclusive breastfeeding prevalence rate found in Dodoma municipality was higher than at national average, it did not meet the recommendations of world health organization. Proper planning and results based programs through the existing system is needed with close monitoring and timely evaluation to transform policy recommendations to action at a field level. Interventions and further research should address the low prevalence of exclusive breast feeding practices in study area. 
Table 2. Socio-demographic characteristics of respondents( $N=200)$

\begin{tabular}{|l|l|l|}
\hline Characteristicsof mothers & \multicolumn{2}{l}{$\%$} \\
\hline Maternal Age (years) & 21 & 10.5 \\
\hline$<19$ & 109 & 54.5 \\
\hline $20-25$ & 53 & 26.5 \\
\hline $26-30$ & 17 & 8.5 \\
\hline$>30$ & & \\
\hline Maternal Education & 43 & 21.5 \\
\hline Illiteracy & 129 & 64.5 \\
\hline primary & 28 & 14.0 \\
\hline Secondary and above & & \\
\hline Maternal Employment & 31 & 15.5 \\
\hline Employed & 38 & 19.0 \\
\hline Self employment(traders) & 131 & 65.5 \\
\hline House wife & & \\
\hline Marital status & 43 & 21.5 \\
\hline Single/disserted/widowed & 157 & 78.5 \\
\hline Married/cohabiting & & \\
\hline Number of children & 48 & 24 \\
\hline One child & 152 & 76 \\
\hline More than one child & & \\
\hline Gender of Baby & 96 & 48 \\
\hline Male & 104 & 52 \\
\hline Female & & 32.5 \\
\hline Place of delivery & 65 & 87.5 \\
\hline Home & 135 & 8.5 \\
\hline Hospital & 183 & \\
\hline Mode of delivery & 17 & \\
\hline Normal vaginal delivery & & \\
\hline Caesarean section & & \\
\hline & & \\
\hline & & \\
\hline
\end{tabular}


Table 3. Knowledge of respondents about exclusive breastfeeding $(\mathrm{N}=200)$

\begin{tabular}{|l|l|l|}
\hline Knowledge on exclusive breastfeeding & $\mathbf{n}$ & $\mathbf{\%}$ \\
\hline Meaning of 'Exclusive Breastfeeding & & \\
\hline Feed only breast milk & 193 & 96.5 \\
\hline Feed only cow's milk & 1 & 0.5 \\
\hline Feed only formula milk & 2 & 1.0 \\
\hline Feed breast milk and other foods & 3 & 1.5 \\
\hline Don't know & 1 & 0.5 \\
\hline duration of exclusive breastfeeding & & \\
\hline birth to six months & $\mathbf{1 8 3}$ & 91.5 \\
\hline birth to four months & $\mathbf{9}$ & 4.5 \\
\hline birth to three months & $\mathbf{8}$ & 4.0 \\
\hline Knowledge (Overall) & & \\
\hline Adequate knowledge & $\mathbf{1 7 8}$ & 89 \\
\hline Inadequate knowledge & $\mathbf{2 2}$ & 11 \\
\hline Main source of breastfeeding education & & \\
\hline Friends/relatives & $\mathbf{9}$ & 4.5 \\
\hline Govt hospital & $\mathbf{1 4 8}$ & 74.0 \\
\hline Private hospital & $\mathbf{3 2}$ & 16.0 \\
\hline Media (TV, radio, etc.) & $\mathbf{1 0}$ & 5.0 \\
\hline others & $\mathbf{1}$ & 0.5 \\
\hline
\end{tabular}

Table 4. Distribution of mothers regarding breastfeeding practice

\begin{tabular}{|l|l|l|}
\hline Brest feeding practices & $\mathbf{n}$ & $\%$ \\
\hline $\begin{array}{l}\text { Time of breastfeeding } \\
\text { initiation }\end{array}$ & & \\
\hline Immediately $(<1 \mathrm{~h})$ & $\mathbf{1 7 8}$ & $\mathbf{8 9}$ \\
\hline $1-24 \mathrm{~h}$ & $\mathbf{1 8}$ & $\mathbf{9}$ \\
\hline$>24 \mathrm{~h}$ & $\mathbf{4}$ & $\mathbf{2}$ \\
\hline $\begin{array}{l}\text { Breastfeeding practice at } \mathbf{6} \\
\text { months }\end{array}$ & & \\
\hline EBF & $\mathbf{1 1 8}$ & $\mathbf{5 9}$ \\
\hline Non-EBF & $\mathbf{9 2}$ & $\mathbf{4 6}$ \\
\hline
\end{tabular}


Table 5. Socio-demographic variables affecting exclusive breast feeding

\begin{tabular}{|c|c|c|c|c|c|}
\hline Variable & Total $\mathbf{N}$ & $\mathbf{n}$ & $\%$ & OR (95\%CI) & $\mathbf{P}$ \\
\hline \multicolumn{6}{|l|}{ Age } \\
\hline$\leq 25$ & 130 & 80 & 61.5 & 1 & \\
\hline$>25$ & 70 & 38 & 54.2 & $13(0.8,2.0)$ & 0.133 \\
\hline \multicolumn{6}{|l|}{ Education } \\
\hline Illiteracy and primary & 172 & 100 & 58.1 & 1 & \\
\hline Secondary and above & 28 & 18 & 64.2 & $1.3(0.5,3.6)$ & 0.562 \\
\hline \multicolumn{6}{|l|}{ Employment } \\
\hline Unemployed/House wife & 131 & 70 & 53.4 & 1 & \\
\hline Employed/Business & 69 & 48 & 69.5 & $1.8(1.3,3.1)$ & 0.005 \\
\hline \multicolumn{6}{|l|}{ Marital status } \\
\hline Married/cohabiting & 157 & 88 & 56.0 & 1 & \\
\hline Single/disserted/widowed & 43 & 30 & 69.7 & $1.8(1.1,3.2)$ & 0.046 \\
\hline \multicolumn{6}{|l|}{ Number of children } \\
\hline More than one child & 152 & 89 & 58.5 & 1 & \\
\hline One child & 48 & 29 & 60.4 & $1.3(0.7,1.8)$ & 0.477 \\
\hline \multicolumn{6}{|l|}{ Knowledge of EBF } \\
\hline Inadequate & 22 & 5 & 22.7 & 1 & \\
\hline Adequate & 178 & 113 & 63.4 & $6.1(3.3,12.2)$ & $<0.001$ \\
\hline \multicolumn{6}{|l|}{ Place of delivery } \\
\hline Home & 65 & 27 & 41.5 & 1 & \\
\hline Hospital & 135 & 91 & 67.4 & $2.8(1.8,4.6)$ & $<0.001$ \\
\hline
\end{tabular}

\section{Acknowledgements}

Author is grateful to his under graduate students who helped him in interviewing the respondents.

\section{Ethics}

Written consent was taken from the respondents who participated in this study.

\section{References}

American Academy of Pediatrics. (2005). Policy statement: Breastfeeding and the use of human milk. Pediatrics 2005, 115, 496-506. http://dx.doi.org/10.1542/peds.2004-2491 
Arifeen S., Black R. E., Antelman G, Baqui A, Caulfield L, \& Becker S. (2001). Exclusive breastfeeding reduces acute respiratory infection and diarrhea deaths among infants in Dhaka slums. Pediatrics 2001, 108(4), E67. http://dx.doi.org/10.1542/peds.108.4.e67

Cohen, L., Manion. L., \& MC Coumick, R. (2001). Research Methods in Education, London, Rout ledge Falmer National Bureau of Statistics (NBS) [Tanzania] and ORC Macro: Tanzania Demographic and Health Survey 2004-05. Dar-Es-Salaam, Tanzania; 2005.

General Report. (2003). 2002 Population and Housing Census, National Bureau of Statistics, Dar Es Salaam,or http://www.tanzania.go.tz/2002census.PDF

Jones G., Steketee R. W., Black RE, Bhutta Z. A., \& Morris S. S. (2003). How many child deaths can we prevent this year? Lancet 2003, 362, 65-71. http://dx.doi.org/10.1016/S0140-6736(03)13811-1

Merten S, \& Ackermann-Liebrich U. (2004). Exclusive breastfeeding rates and associated factors in Swiss baby-friendly hospitals. Journal of Human Lactation, 20(1), 9-17. http://dx.doi.org/10.1177/0890334403261017

Riva E, Banderali G, Agostoni C, Silano M, Radaelli G, \& Giovannini M. (1999). Factors associated with initiation and duration of breastfeeding in Italy. Acta Paediatrica 1999, 88, 411-415. http://dx.doi.org/10.1111/j.1651-2227.1999.tb01132.x

Roig A. O., Martinez M. R., Garcia J. C., Hoyos S. P., Navidad G. L., Alvarez J. C., Pujalte Mdel M, De Leon Gonzalez R.G. (2001). Factors associated to breastfeeding cessation before 6 months. Rev Lat Am Enfermagem 18(3):373-380. World Health Organization: WHO Expert committee report. Geneva, WHO.

The united Tanzanian website. (2011). Regions, Dodoma,http://www.tazania.go.tz/regions.

World Health Organization: Global Strategy on Infant and Young Child Feeding. (2002). [http://webitpreview.who.int/entity/nutrition/publications/gs_infant_feeding_text_eng.pdf] webcite 55th World Health Assembly Geneva, Switzerland.

World Health Organization: Infant and young child feeding: Model Chapter for textbooks for medical students and allied health professionals. (2009). Geneva. 